\title{
Wenckebach phenomenon occurring in the distal conducting system in a young adult
}

\author{
Richard Gray, V. S. Kaushik, and William J. Mandel ${ }^{1}$ \\ From the Department of Cardiology, Cedars-Sinai Medical Center, and the Department of Medicine, University \\ of California at Los Angeles, U.S.A.
}

This report describes the case of a young man who presented with right bundle-branch block and second degree atrioventricular block; intermittent episodes of Wenckebach periods were recorded. His bundle electrograms demonstrated progressive prolongation of the HV interval followed by block occurring distal to His. This report emphasizes the fact that the Wenckebach phenomenon as a manifestation of the distal conducting system disease can occur in young adults. The observations lend credence to the concept that Lenègre's disease can occur in young people.

The development of techniques for recording intracardiac electrograms has enabled the clinician to localize more precisely the site of atrioventricular block in man (Damato et al., 1969; Scherlag et al., 1969; Rosen et al., 1970; Narula et al., 1971). The clinical importance of localizing the area responsible for atrioventricular block is that this can be related to the prognosis of the various subgroups of atrioventricular block. Studies using intracardiac recording techniques have established that the majority of patients with second degree atrioventricular block with Wenckebach periods have progressive $\mathrm{AH}$ interval prolongation, with the site of block being localized to the area of the atrioventricular junction (type I) (Damato et al., 1969; Narula et al., 197I). In general, these patients have a benign course (Langendorf and Pick, 1968). In contrast, the majority of patients with second degree atrioventricular block of the type II variety appear to have lesions localized in the distal conduction system below the bundle of His (Damato et al., 1969; Narula et al., I97I). These patients with distal conduction system disease appear to have a poor prognosis and require permanent pacemaker therapy (Donoso, Adler, and Friedberg, 1964; Langendorf and Pick, 1968).

In a small group of elderly patients with heart disease, the occurrence of the Wenckebach phenomenon caused by conduction delay below the bundle of His has been suggested by observations using standard electrocardiograms, and documented by His bundle electrograms (Friedberg and Schamroth,

${ }^{1}$ Milly Factor Clinical Investigator of the Western Cardiac Foundation.
1969; Narula and Samet, 1970; Narula et al., 1971). It is the purpose of this communication to report an instance of symptomatic Wenckebach phenomenon caused by block distal to the bundle of His in a young man.

\section{Case report}

A 28-year-old man employed as a foreman at a factory was admitted to hospital for evaluation of recent onset of light-headedness, shortness of breath, and vague substernal discomfort occurring after heavy exertion. The patient stated that he was completely well until one week before admission. He was athletically inclined and did long distance running on a daily basis without symptoms before the recent episode. Family history revealed only evidence of maternal hypertension. Physical examination demonstrated a pulse of $50 / \mathrm{min}$ which was regular and a blood pressure of $155 / 60 \mathrm{mmHg}(20.6 / 8.0 \mathrm{kPa})$. Pertinent physical findings included a sharply rising carotid pulse with a bifid character and a grade $2 / 6$ midsystolic murmur heard best at the base and left sternal edge.

Chest $x$-ray was within normal limits. Electrocardiogram showed right bundle-branch block with 2:I atrioventricular conduction (Fig. IA). A ro-hour Holter monitor recording demonstrated intermittent episodes of Wenckebach periodicity as well as $2: 1$ atrioventricular conduction (Fig. IB). Echocardiograms were within normal limits and apex cardiograms did not reveal a double systolic anterior impulse or a prominent a wave.

The patient underwent right and left heart catheterization, left ventriculography, and coronary angiography, all of which were within the normal range. In addition, His bundle recordings were obtained with atrial pacing. The His bundle recordings, obtained during sinus rhythm, demonstrated a normal AH interval $(90 \mathrm{~ms})$ and a pro- 
A.

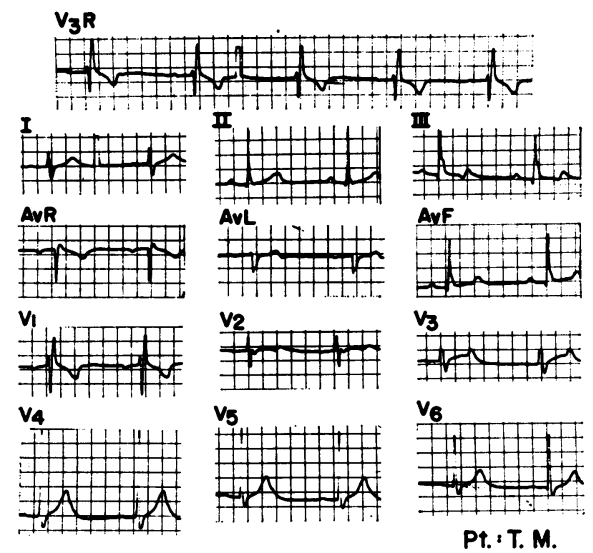

B.

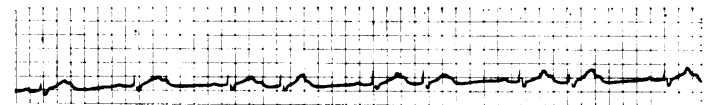

FIG. I Electrocardiogram and rhythm strip during sinus rhythm. Panel $A$ shows the standard electrocardiogram with evidence of $2: 1$ conduction and right bundle-branch block. Note the rightward shift in frontal plane axis, with clockwise direction suggesting possible posterior fascicular block. Furthermore, the $P R$ interval in the conducted beats is $0.24 \mathrm{~s}$. Panel B shows a representative strip from a Io-hour Holter recording, showing 2:I conduction alternating with 3:2 Wenckebach periods.

nounced prolongation of the $\mathrm{HV}$ time ( $175 \mathrm{~ms})$. Atrial pacing at rates of $70 / \mathrm{min}$ resulted in prolongation of both the AH (I IO ms) and the HV intervals ( $190 \mathrm{~ms}$ ). Increasing the heart rate to $80 / \mathrm{min}$ by atrial pacing resulted in the development of Wenckebach periods which occurred because of progressive HV delay; block of the sinus impulse occurred distal to the His bundle (Fig. 2).

A permanent QRS-inhibited ventricular demand pacemaker was implanted the day after cardiac catheterization. Subsequent follow-up has revealed no significant recurrence of symptoms.

\section{Discussion}

Classification of the type of atrioventricular block has been of great interest to the clinician since the description of various forms of atrioventricular block in the early part of the twentieth century. Nevertheless, adequate therapy was not available for the treatment of advanced forms of atrioventricular block until the introduction of permanent transvenous pacemakers in 1959 (Furman and
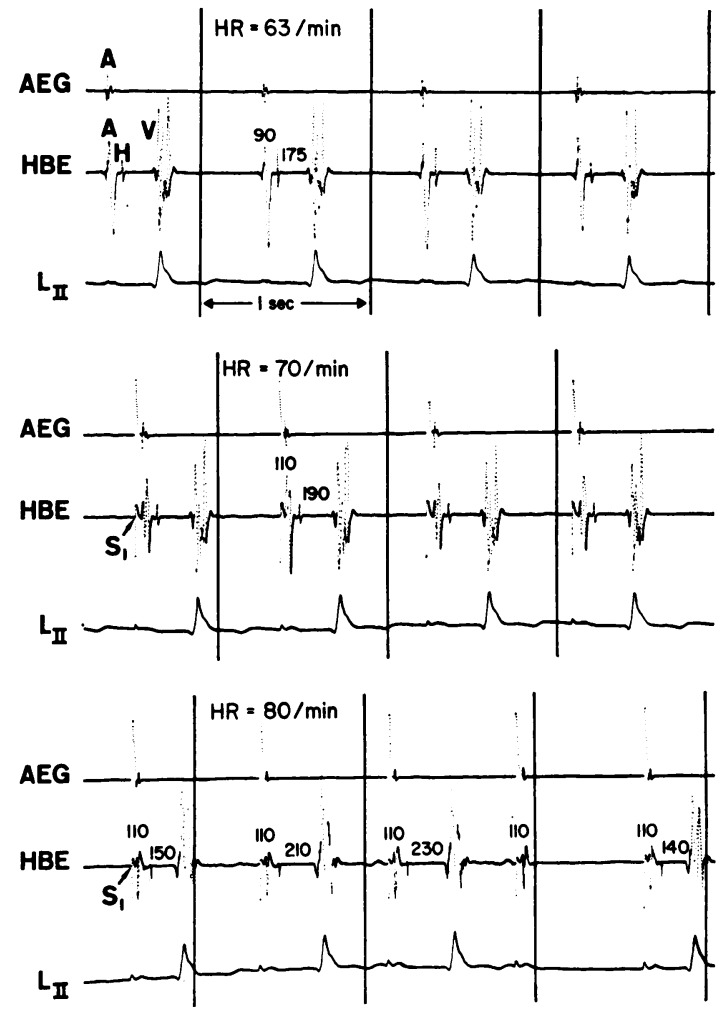

FIG. 2 His bundle electrogram. The upper panel shows the recording obtained during sinus rhythm at a heart rate of 63 beats/min; a I s time calibration is shown at the bottom of the panel. To the left of the panel are shown the abbreviations for the high right atrial electrocardiogram ( $A E G)$, the His bundle electrogram ( $H B E)$, and the lead II electrocardiogram. A signifies atrial depolarization, $\mathrm{H}$ the His bundle deflection, and $\mathrm{V}$ ventricular depolarization. Listed above the second complex on the His bundle tracing are the $A H$ interval $(90 \mathrm{~ms}$ ) and the $H V$ interval ( $175 \mathrm{~ms}$ ). The middle panel shows the recording obtained during atrial pacing at a rate of $70 / \mathrm{min}$. $\mathrm{S}_{1}$ signifies the stimulus artefact; the $A H$ interval was $110 \mathrm{~ms}$ and the $H V$ interval was $190 \mathrm{~ms}$. The lower panel shows the recording obtained during atrial pacing at a rate of $80 / \mathrm{min}$. An example of a $4: 3$ Wenckebach period is shown with progressive pro. longation of the $H V$ intervals with a fixed $A H$ interval (IIO ms).

Robinson, 1959). This led to the need for more accurate assessment of location of atrioventricular block.

Introduction of intracardiac recording techniques for use in man now greatly simplifies the character- 
ization and localization of the various types of atrioventricular block (Scherlag et al., 1969). Data accumulated over the past years have shown that, contrary to previously accepted views, various forms of atrioventricular block could occur because of conduction delay in a large number of sites within the atrioventricular conducting system (Damato et al., 1969; Rosen et al., 1970; Narula et al., 197I).

Specific emphasis has been given to the identification of the site of block in patients with second degree atrioventricular block. This was felt to be important by the clinician as, prognostically, Wenckebach periods (type I) have been generally felt to be benign, whereas patients who exhibited second degree atrioventricular block of type II frequently required permanent pacemaker therapy (Langendorf and Pick, I968). In this context, it has been emphasized that the site of atrioventricular block could be localized from the standard electrocardiogram. Dreifus and co-workers (1971) have suggested that the presence of a narrow $Q R S$ generally infers atrioventricular junctional disease, whereas the presence of a wide QRS identifies distal conducting system disease. Additional observations by Dhingra et al. (1974a) have indicated that, in general, Wenckebach periods in patients with pre-existing bundle-branch block suggest conduction delay proximal to the His bundle.

Further investigations in patients with second degree atrioventricular block have emphasized that Wenckebach periods, with the site of block being atrioventricular nodal, may be seen in the young patient who is otherwise without evidence of heart disease (Cullen and Collin, 1964; Lightfoot et al., 1973). Nevertheless, second degree atrioventricular block of the type II variety is almost exclusively observed in elderly patients with advanced heart disease (Donoso et al., 1964; Damato et al., 1969; Friedberg and Schamroth, 1969; Narula and Samet, 1970; Narula et al., 1971).

An earlier report described the natural history of a 40-year-old patient who developed intermittent advanced heart block at age 3I (Dhingra et al., 1974b). Their patient was considered to be the youngest patient reported with Lenègre's disease. Therefore, the data obtained in our patient offer support to Dhingra's observation that Lenègre's disease may occur in young adults.

The observations in the present report serve to document: ( $I$ ) that Wenckebach periodicity can occur in the distal conducting system; (2) that distal conducting system disease (? Lenègre's disease) can be identified in young patients without other identifiable forms of heart disease; and (3) the difficulty in identifying the site of atrioventricular block solely on electrocardiographic criteria.

\section{References}

Cullen, K. J., and Collin, R. (1964). Daily running causing Wenckebach heartblock. Lancet, 2, 729.

Damato, A. N., Lau, S. H., Helfant, R., Stein, E., Patton, R. D., Scherlag, B. J., and Berkowitz, W. D. (1969). A study of heart block in man using His bundle recordings. Circulation, 39, 297.

Dhingra, R. C., Denes, P., Wu, D., Chuquimia, R., and Rosen, K. M. (1974a). The significance of second degree atrioventricular block and bundle branch block. Circulation, 49, 638.

Dhingra, R. C., Khan, A., Pouget, J. M., and Rosen, K. M. (1974b). Lenègre's disease in a young adult. American Heart fournal, 88, 487.

Donoso, E., Adler, L. N., and Friedberg, C. K. (1964). Unusual forms of second-degree atrioventricular block, including Mobitz Type-II block, associated with the Morgagni-Adams-Stokes syndrome. American Heart fournal, 67, 150.

Dreifus, L. S., Watanabe, Y., Haiat, R., and Kimbiris, D. (1971). Atrioventricular block. American fournal of Cardiology, 28, 371 .

Friedberg, H. D., and Schamroth, L. (1969). The Wenckebach phenomenon in left bundle branch block. American Fournal of Cardiology, 24, 59r.

Furman, S., and Robinson, G. (1959). The use of an intracardiac pacemaker in the correction of total heart block. Surgical Forum, 9, 245.

Langendorf, R., and Pick, A. (1968). Editorial. Atrioventricular block, type II (Mobitz): its nature and clinical significance. Circulation, 38, 8 I9.

Lightfoot, P. R., Sasse, L., Mandel, W. J., and Hayakawa, H. (I973). His bundle electrograms in healthy adolescents with persistent second degree A-V block. Chest, 63, 358.

Narula, O. S., and Samet, P. (1970). Wenckebach and Mobitz Type II A-V block due to block within the His bundle and bundle branches. Circulation, 41, 947.

Narula, O. S., Scherlag, B. J., Samet, P., and Javier, R. P. (197I). Atrioventricular block. American fournal of Medicine, 50, 146.

Rosen, K. M., Loeb, H. S., Chuquimia, R., Sinno, M. Z., Rahimtoola, S. H., and Gunnar, R. M. (1970). Site of heart block in acute myocardial infarction. Circulation, 42, 925.

Scherlag, B. J., Lau, S. H., Helfant, R. H., Berkowitz, W. D., Stein, E., and Damato, A. N. (1969). Catheter technique for recording His bundle activity in man. Circulation, 39, 13.

Requests for reprints to Dr. Richard Gray, Department of Cardiology, Cedars-Sinai Medical Center, 4833 Fountain Avenue, Los Angeles, California 90029, U.S.A. 